\title{
The use of information technology in the DSTU new campus business center life cycle operational phase management
}

\author{
Olga Vorontsova*, Yuliya Shvets, and Svetlana Sheina \\ Don State Technical University, 1 Gagarin sq., Rostov-on-Don, 344000, Russia
}

\begin{abstract}
The article describes the information technology effective use possibilities in the building technical condition management within the operational phase of the building's life cycle. In the course of the work, the most important stage for assessing the application of technologies is the operation stage, which is the longest and most expensive in the life cycle of a building. The main characteristics of the designed object are given. The main benefits from the information technologies use at the stage of building operation are outlined. The building life cycle cost analysis for three operational models is presented.
\end{abstract}

\section{Introduction}

Construction is an important area for the state economy formation. According to the calculations of the Analytical Center of Russian Federal State Statistic Service, construction accounts for 5.1\% of GDP structure in terms of production in 2017-2020 [1].

The construction of any real estate object requires significant financial, time and labor costs. The created objects form an urban environment for people to live and work as well as their social activities. The average life cycle of a capital building is about 100 years, during which it is necessary to carry out timely maintenance, maintenance of structures and engineering equipment of the building, to carry out reconstruction and major repairs. It is necessary to maintain its physical and moral deterioration at a satisfactory level for the normal building functioning. So, the building technical condition management is important from an investment point of view in terms of assessing the cost of the life cycle of an existing or building under construction, as well as from a technical point of view, in terms of maintaining the condition of a building for its normal functioning and maximum possible long quality life cycle.

At the present development stage of the construction activities, integrated building management at the operational stage can be carried out on the basis of information technologies, relying on the existing facilities' databases.

Currently, increasing the construction industry efficiency is focused on the introduction of BIM technologies into the practice of design organizations and the organizations involved in the buildings and structures' operation (BIM - Building Information Modeling). BIM implementation is a complex process that requires the participation of a large number of

\footnotetext{
*Corresponding author: vorontsovaolyaa@mail.ru
} 
specialists. The system is complex, also because each specialist must acquire new skills in order to work with the system. In addition, this process requires large financial investments. Despite these requirements, the implementation of BIM requires active support from both the state and construction specialists, since at present it is the most affordable and promising option for the development of the construction industry in terms of project monitoring and cooperation between the disciplines.

\section{Materials and methods}

In this article, an example of managing the technical condition of a building, as well as the cost and quality assessment of its life cycle using the example of a business center located on the Don State Technical University (hereinafter - DSTU) new campus territory will be considered. The project was created to meet the needs of the university in the formation of a technological environment, training of highly qualified personnel for the labor market. [2] The development of the campus environment allows to expand the learning environment for students, to increase the university attractiveness for new applicants due to the opportunities provided in the field of student development and increases university competitiveness.

When creating the architectural concept of the business center, the principle of open spaces was used. Such a scheme gives an opportunity to effectively use the space for various purposes, if necessary, changing its purpose without losing the comfort and efficiency of its use. Attention is paid to the possibility of using university computers and personal computers for the students and visitors' work at the business center, since almost any educational and work process requires their use at present.

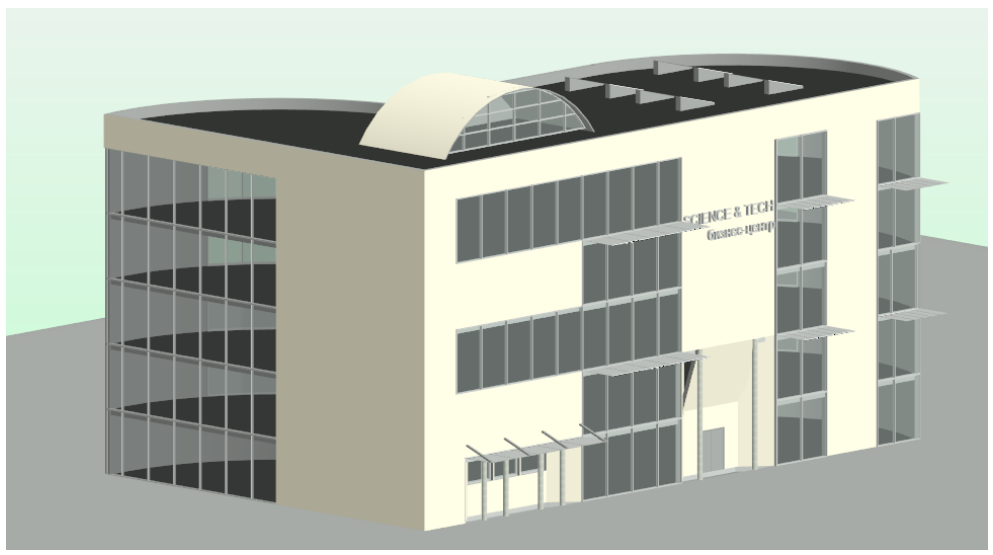

Fig. 1. The projected business center on the DSTU campus, Gagarin sq., Rostov-on-Don

The most important part in project pricing, its investment justification is the determination of cost indicators for each construction stage. The investment justification makes it possible to determine the feasibility of creating a project, its economic efficiency at the pre-investment stage, to minimize future costs, to make the necessary amendments to the project to achieve the result expected by the investor in the ratio of costs, construction volume, performance of the projected building or structure.

The most financially costly and longest phase of a building existence is the operation phase. Based on the results of calculations made within the framework of the study, the investments are $5-7 \%$ lower at the design stage, and construction is 3 times less than the cycle operational phase cost. 


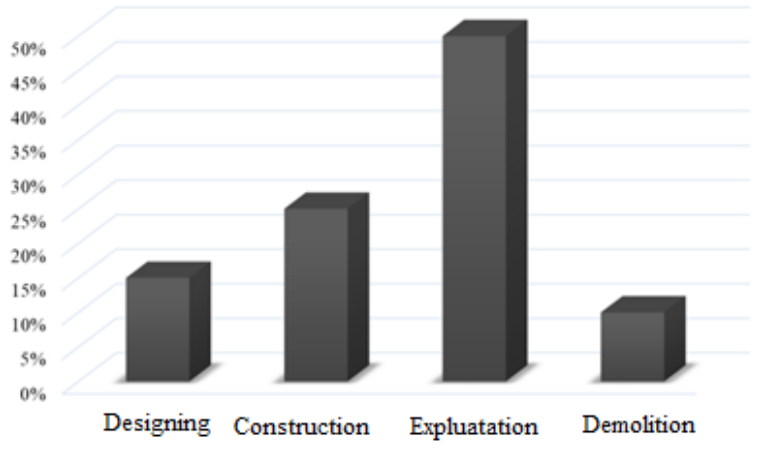

Fig. 2. Life Cycle Cost Sharing Scheme

The total cost of creating a new campus is estimated at 8.0 billion rubles. The sources of financing the project are the investor's funds in the amount of $30 \%$, which is 2,400 million rubles, $70 \%$ - the creditor's funds in the amount of 5,600 million rubles [3].

The costs of erection, maintenance, reconstruction and demolition of a building are inevitable. Calculation of the building life cycle cost allows to make the necessary adjustments to the project if necessary, at the design stage. Making adjustments at the design stage can significantly save the investor's time and financial resources, which is an important criterion for a competitive selection of a project. Based on the life cycle cost calculation, it is possible to make changes in the choice of building materials, products, structures, installed equipment and to justify the technical and economic indicators of the object.

The cost calculation can also be used to compare multiple projects of the same type with similar performance based on different operating costs. Thus, the main advantage of analyzing the planned project total cost assessment is to ensure the selection of the most profitable and rational decisions for the project, to estimate the planned cost of the entire life cycle of the object [4].

The authors have developed a BIM model of the building as a project part. The model can serve as a tool for tracking the existing properties of an object. The basis for the model development is a complete set of design documentation for construction. The model, developed on the basis of the documentation, contains the most complete information about the equipment used in the operation of the building and its properties. The availability of an up-to-date information model corresponding to the actual state of the building, and the possibility of its rational use will reduce the cost of operating equipment, optimize the time spent on planned and emergency repairs that may occur during the building daily operation, as well as during natural aging. The service life of the building is about one hundred years. During this long period, several repairs or reconstructions are planned, which means that different people will work with the project documentation. Errors and inconsistencies that need to be corrected may appear in the documentation. Documentation engineers will spend more time fixing identified deficiencies, which is extremely inefficient in terms of both time and financial resources.

Nevertheless, being the most complete source of information, a BIM model is only a tool for storing information about a construction object. In order to be able to effectively manage the building during the operation phase, plan its maintenance, improve the quality of work and subsequently reduce the costs of all processes related to the use of the facility, it is necessary to use complex systems that allow storing and processing information. To calculate the costs of the project for the purpose of long-term sustainable planning and project management, the system was chosen as an information and analytical base IAS housing and utility infrastructure. The work of the "Information and Analytical System Housing and Utility Infrastructure» is aimed at analyzing the technical, architectural and planning data on 
the object. The program is designed to determine the need for repair work at the studied stage of the building's life cycle, calculate the replacement cost required to replenish the physical and moral deterioration of the building.

The program also makes it possible to analyze the building's life cycle efficiency based on three main operating models: this is a model without maintenance and major repairs, taking into account only the natural aging of the building; a model that takes into account the repair of the main structural elements and life support systems; a model that takes into account the timely repair of all systems and building elements.

Evaluation of the results obtained from the models designed by the system makes it possible to estimate the need for repairs based on the data obtained on the deterioration of the building.

The life cycle modeling methodology consists of 5 stages.

Stage 1 - the formation of an object passport in the system IAS housing and utility infrastructure. The passport of the object must contain all the available characteristics of the building and its engineering networks.

Stage 2 - the implementation of modeling the life cycle of the building, taking into account the type of repair work carried out.

Stage 3 - calculating the cost of the full life cycle of the object.

Stage 4 - a comparative analysis of the results obtained on the basis of the calculation of the terms of effective operation, depending on the type of repair. Stage 5 - selection of the most effective model of object operation.

The investigated object is a 5-storey business center, designed in 2021. Construction site - Rostov region, Rostov-on-Don, Mechnikov str., 81 / 2s.

The operational phase was simulated according to the three models described above: taking into account complete (model 3), partial repair (model 2) and with no repair work (model 1).

The results of modeling the operational phase of a business center, model 1, are shown in Figure 3.

\begin{tabular}{|c|c|c|c|}
\hline \multicolumn{2}{|c|}{ Replacement cost, rubles } & \multicolumn{2}{c|}{ Cost estimate of physical depreciation, rubles } \\
\hline For the whole building & $\begin{array}{c}\text { For basic structural } \\
\text { elements }\end{array}$ & For the whole building & $\begin{array}{c}\text { For basic structural } \\
\text { elements }\end{array}$ \\
\hline 170646335,0 & 34948369,42 & 33040381,57 & 11513271,8 \\
\hline \multicolumn{2}{|c|}{ Obsolescence valuation } & \multicolumn{2}{c|}{ Repair efficiency factor } \\
\hline For the whole building & $\begin{array}{c}\text { For basic structural } \\
\text { elements }\end{array}$ & For the whole building & $\begin{array}{c}\text { For basic structural } \\
\text { elements }\end{array}$ \\
\hline 7185184,11 & 7185184,11 & 0,27 & 0,83 \\
\hline
\end{tabular}

Fig. 3. Operational Phase Simulation Results Model 1 by 2041

In 20 years, the physical deterioration of the heating system and the power supply system will reach $75 \%$. Such wear characterizes the further operation of the facility as impossible due to the high destruction of structural elements and engineering equipment. The effective operation term for this model was 20 years, which is $14 \%$ of the building standard service life $[5,6]$.

The results of calculations made on the model 2 basis, which takes into account the repair of structural elements, the complete elimination of their physical wear, are shown in Figure 4. 


\begin{tabular}{|c|c|c|c|}
\hline \multicolumn{2}{|c|}{ Replacement cost, rubles } & \multicolumn{2}{c|}{ Cost estimate of physical depreciation, rubles } \\
\hline For the whole building & $\begin{array}{c}\text { For basic structural } \\
\text { elements }\end{array}$ & For the whole building & For basic structural elements \\
\hline 170988298,4 & 35018403,5 & 163816740,7 & 6376539,8 \\
\hline \multicolumn{2}{|c|}{ Obsolescence valuation } & \multicolumn{2}{c|}{ Repair efficiency factor } \\
\hline For the whole building & $\begin{array}{c}\text { For basic structural } \\
\text { elements }\end{array}$ & For the whole building & For basic structural elements \\
\hline 7185023,1 & 7185023,1 & 1,00 & 0,22 \\
\hline
\end{tabular}

Fig. 4. Operational Phase Simulation Results Model 2 by 2041

The recommended type of repair is reconstruction, modernization for the building as a whole, and complex overhaul for the main structural elements and life support systems. When the building is operated according to the 2 nd model, the effective service life is 129 years, or $86 \%$ of the standard service life. The cost estimate of the physical deterioration of the building as a whole by 2150 will amount to 164 million rubles, the building will be effectively operated for 129 years $[5,6]$.

The technical state of the building structural elements according to the $3 \mathrm{rd}$ model at different periods of the building's life cycle and the costs of eliminating physical wear are shown in Figure 5.

\begin{tabular}{|c|c|c|c|}
\hline \multicolumn{2}{|c|}{ Replacement cost, rub } & \multicolumn{2}{c|}{$\begin{array}{c}\text { Cost estimate of physical wear and } \\
\text { tear, rub. }\end{array}$} \\
\hline $\begin{array}{c}\text { For the building } \\
\text { as a whole }\end{array}$ & $\begin{array}{c}\text { For the main } \\
\text { constructive } \\
\text { elements }\end{array}$ & $\begin{array}{c}\text { For the building } \\
\text { as a whole }\end{array}$ & $\begin{array}{c}\text { For the main } \\
\text { constructive elements }\end{array}$ \\
\hline 170646335.0 & 27739992.2 & 136830972.7 & 458987.4 \\
\hline \multicolumn{2}{|c|}{ Cost estimate of obsolescence } & \multicolumn{2}{|c|}{ Repair efficiency factor } \\
\hline $\begin{array}{c}\text { For the building } \\
\text { as a whole }\end{array}$ & $\begin{array}{c}\text { For the main } \\
\text { constructive } \\
\text { elements }\end{array}$ & $\begin{array}{c}\text { For the building } \\
\text { as a whole }\end{array}$ & $\begin{array}{c}\text { For the main } \\
\text { constructive elements }\end{array}$ \\
\hline 7194226.7 & 7194226.7 & 0.75 & 0.20 \\
\hline
\end{tabular}

Fig. 5. The results of modeling the operational phase of the facility for 3 models in 2171

The life cycle consists of the following five stages: design, construction, commissioning, operation and maintenance, disposal. Based on the allocation of individual stages, it is also possible to single out the life cycle costs, taking into account the share of each type of cost in the total cost of capital construction. [7]

To calculate the full life cycle cost of the object under consideration, it is necessary to use the estimated cost of construction, as well as the reduced costs of repair work during the operational period of the life cycle (the standard operation period is 150 years) [8].

Calculation of the cost of the full life cycle $(\mathrm{Clc})$ is made according to the formula 1 .

$$
C l c=C \operatorname{cse}+C d s w+C r w+C l
$$

where: Ccse defines the construction cost - 126 million rubles (according to the summary estimate);

$C d s w$ is the cost of design and survey work - 5\% of the cost of construction;

$\mathrm{Crw}$ is the cost of repair work received on the 2 nd and 3rd models for 100 years;

$\mathrm{Cl}$ shows the facility liquidation cost $-10 \%$ of summary estimate $[9,10]$.

Below is the data from the information system IAS housing and utility infrastructure for modeling the technical state of the object according to the 2nd model (Figure 6,7). 


\begin{tabular}{|c|c|c|c|c|}
\hline Year built & Numbe & Number of floors & 5 & at Work performed \\
\hline \multicolumn{2}{|c|}{ Repair costs } & \multicolumn{2}{|c|}{ Efficiency of repair works } & Technical condition monitoring \\
\hline \multicolumn{5}{|c|}{ Calculation of costs (in current prices) for repair work } \\
\hline \multicolumn{2}{|c|}{ Calculated parameters } & \multicolumn{2}{|c|}{ For the whole building } & For basic structural elements \\
\hline Replacemer & & \multicolumn{2}{|c|}{170988298,40} & 35018403,51 \\
\hline Cost estima & preciation, rubles & \multicolumn{2}{|c|}{163816740.70} & 6376539,87 \\
\hline \multicolumn{2}{|c|}{$\begin{array}{l}\text { The coefficient of the reduced costs for } \\
\text { the elimination of physical wear }\end{array}$} & \multicolumn{2}{|r|}{0.96} & 0.18 \\
\hline \multicolumn{2}{|c|}{ Cost estimate of obsolescence, rubles } & \multicolumn{2}{|c|}{7185023.09} & 7185023,09 \\
\hline \multicolumn{2}{|c|}{$\begin{array}{l}\text { Coefficient of reduced costs for the } \\
\text { elimination of obsolescence }\end{array}$} & \multicolumn{2}{|r|}{0.04} & 0.04 \\
\hline \multicolumn{2}{|c|}{ Repair efficiency factor } & & 1.00 & 0.22 \\
\hline \multicolumn{2}{|c|}{ Recommended type of repair } & reconst & tion, modernization & current \\
\hline
\end{tabular}

Fig. 6. Calculation of the cost of repair work

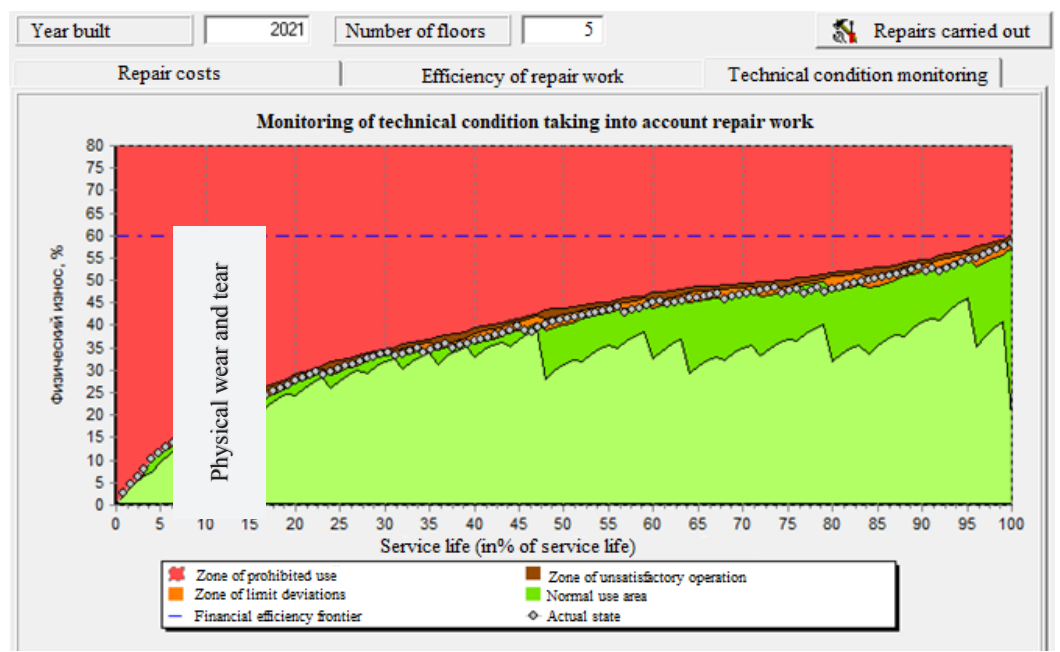

Fig. 7. Condition monitoring taking into account the repair work, model 2

The cost of the full life cycle for the 2 nd model is 198 million rubles.

The cost sharing scheme for the 2 nd model is shown in Figure 8.

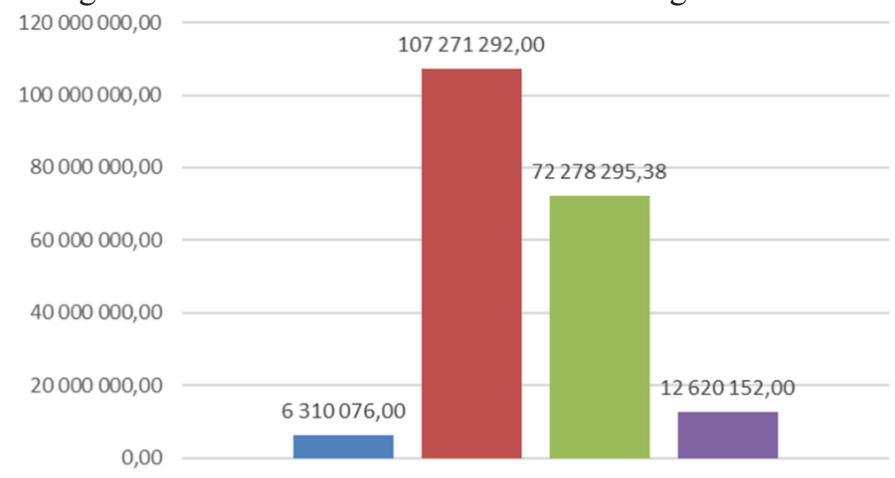

" Design $\mid$ Construction $\mid$ Renovation $\mid$ Demolition

Fig. 8. Cost sharing scheme at the life cycle stages according to the 2 nd model 
Below is the data from the information system IAS housing and utility infrastructure for modeling the technical state of the object according to the 3rd model (Figure 9, 10).

\begin{tabular}{|c|c|c|c|c|}
\hline Year built & \multicolumn{2}{|c|}{ Number of floors } & 5 & \multirow{2}{*}{ Technical condition monitoring | } \\
\hline & \multicolumn{3}{|c|}{ Efficiency of repair works } & \\
\hline \multicolumn{5}{|c|}{ Calculation of costs (in current prices) for repair work } \\
\hline \multicolumn{2}{|c|}{ Calculated parameters } & \multicolumn{2}{|r|}{ For the whole building } & For basic structural elements \\
\hline Replacemen & & \multicolumn{2}{|r|}{170988298,40} & 27739992,20 \\
\hline Cost estimat & preciation, rubles & \multicolumn{2}{|r|}{136830972,70} & 4578987,36 \\
\hline \multicolumn{2}{|c|}{$\begin{array}{l}\text { The coefficient of the reduced costs for } \\
\text { the elimination of physical wear }\end{array}$} & \multicolumn{2}{|r|}{0.72} & 0.17 \\
\hline \multicolumn{2}{|c|}{ Cost estimate of obsolescence, rubles } & & 7194226,67 & 7194226,67 \\
\hline \multicolumn{2}{|c|}{$\begin{array}{l}\text { Coefficient of reduced costs for the } \\
\text { elimination of obsolescence }\end{array}$} & & 0,04 & 0,04 \\
\hline \multicolumn{2}{|c|}{ Repair efficiency factor } & & 0.75 & 0.20 \\
\hline \multicolumn{2}{|c|}{ Recommended type of repair } & & complex & current \\
\hline
\end{tabular}

Fig. 9. Cost sharing scheme at the stages of the life cycle according to the $3 \mathrm{rd}$ model

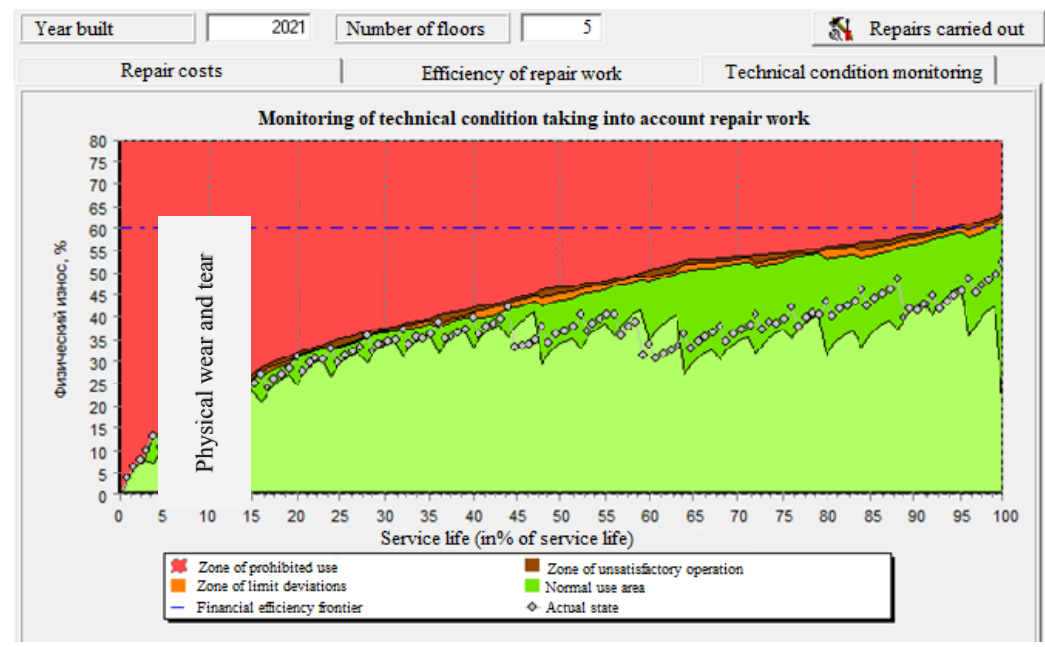

Fig. 10. Condition monitoring taking into account repair work, model 3

Thus, the cost of the building full life cycle according to the $3 \mathrm{rd}$ model will be 469 million rubles. The cost sharing scheme for the 3rd model is shown in Figure 11.

After analyzing the entire life cycle costs for the object, it can be concluded that the operating costs for 3 models, taking into account the repair of all elements and normal operation, the entire standard period of the object of the first capital group constitute the largest part of the costs.

Another tool for city information management - GIS- technology (Geographic Information System) is an information system that makes it possible to store, manage and analyze spatial data. GIS makes it possible to get any spatial information from the generated maps. Esri software is supportive in analyzing and maintaining the entire infrastructure lifecycle - from planning and design to survey, construction management and maintenance [11]. 


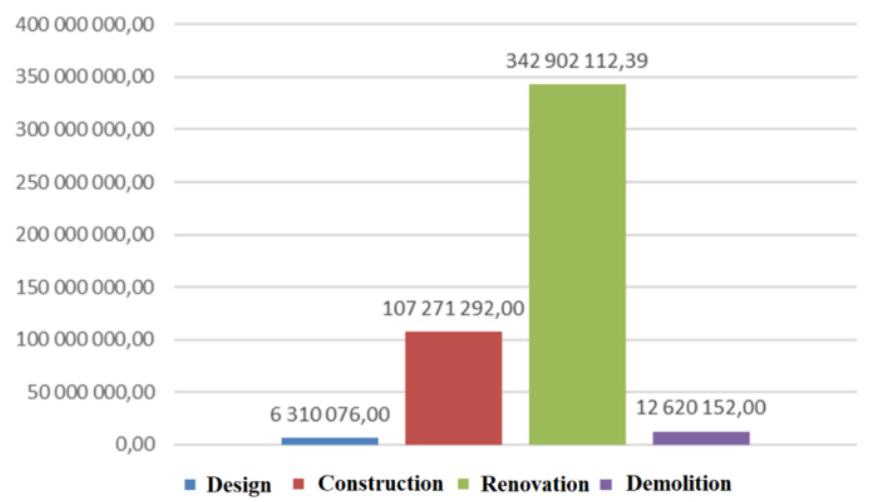

Fig. 11. Cost sharing scheme at the life cycle stages according to the $3 \mathrm{rd}$ model

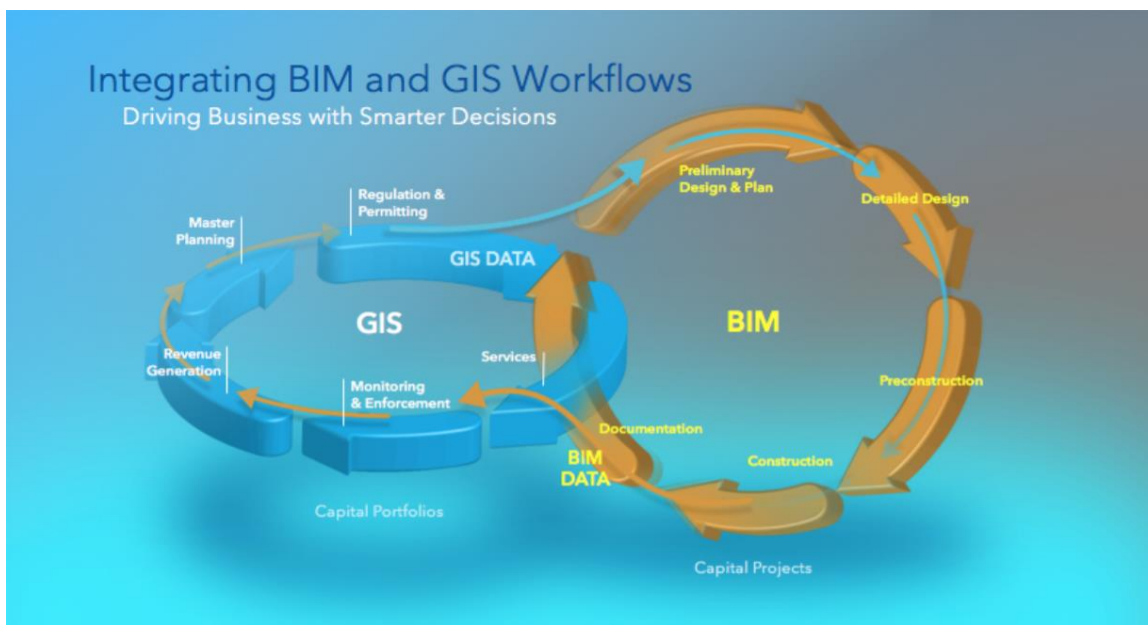

Fig. 12. Interaction GIS and BIM [12]

Sharing BIM and GIS in the complex makes it possible to expand spatial information through visualization. It is possible, for example, to evaluate the spatial scheme of the city according to various criteria, analyze the equipment of the city, choose a more advantageous location of the future building in the city, not only based on the opinion of an expert, but also on the basis of the criteria selected for this object. GIS is used to create 2D visualization and analysis of information about the existing buildings, structures, transport infrastructure, environment.

In the course of development, the authors of the project analyzed the project location in terms of environmental and hydrological factors, in terms of location in urban development. Some of the graphical results of the analysis are shown in Figure 13. Thus, the use of GIS is an advantage not only for infrastructure design, but also for construction and monitoring. The use of a complex of information technologies is an advantage in terms of urban construction, territorial planning.

\section{Results and discussion}

So, on the basis of the calculations, we have calculated the operational phase cost of the investigated object. The presence of this information about the object will allow the best planning of the project management: for example, to add new solutions that will give a 
possibility to reduce the payback period of the project, to consider the prospects for its use in order to obtain funds that in the future will be spent on building maintenance. For example, to add commercial space for rent to the project. The next opportunity is to change the materials selected for the construction, the introduction of energy efficient technologies. From the long-term sustainable development point of view, energy efficient technologies will save the financial resources necessary for the further maintenance of the building.
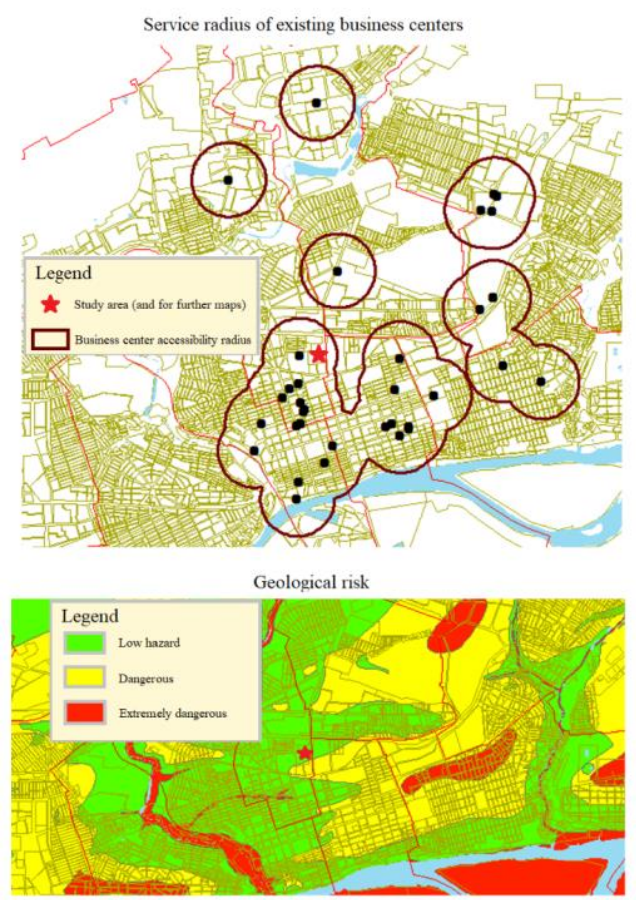
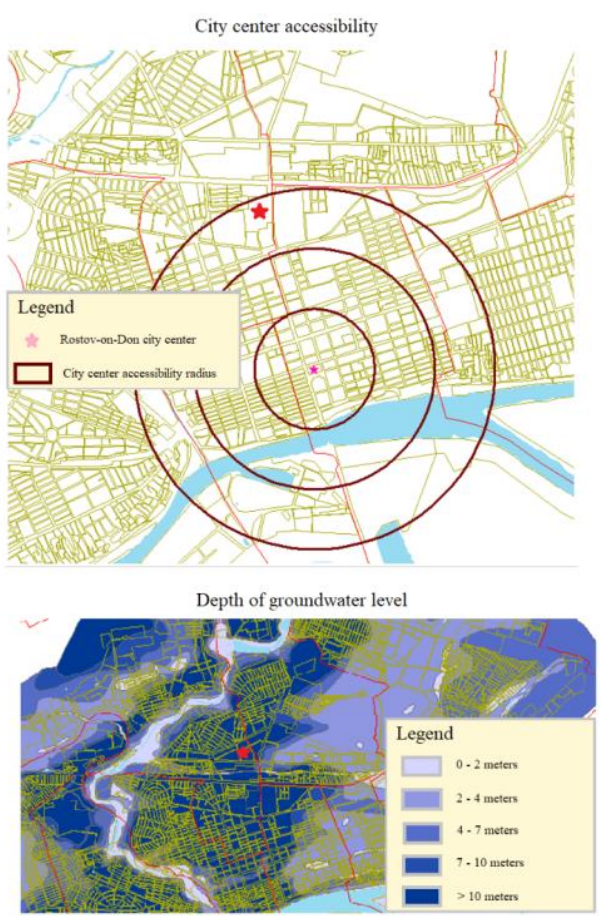

Fig. 13. Assessment of the planned project location in ArcDIS system

\section{Conclusion}

At the present stage of construction industry development, it is necessary to make a longterm analysis, a plan for the management of an object based on the technologies already available today.

The implementation of BIM permits the creation of a "digital twin" of each building, which will reduce the cost of construction, design and future renovations. Building condition assessment software such as IAS housing and utility infrastructure, improves the efficiency of future repairs and allows the investor to assess future costs and opportunities for project changes. The use of GIS will make it possible to assess the object location as fully as possible from the point of view of spatial planning. Thus, the integrated use of information products will allow achieving the most effective management of both individual objects. So, it is in urban areas.

The product of the construction industry is long-lived capital assets that shape the urban environment for human everyday life. Project management based on information technology makes it possible to increase the project efficiency in terms of investment, improve the quality of ongoing and planned work at the facility, develop a strategy for facility management A positive result, achieved by increasing the efficiency of a separate project with the information technology introduction will make it possible to qualitatively develop 
the construction industry, improve the quality of ongoing reconstruction and construction projects, and also have a positive effect on the general economic situation, the quality of projected facilities and the urban environment.

\section{References}

1. Bulletin on current trends in the Russian economy [Electron. resource]. Access mode: https://ac.gov.ru/uploads/2-Publications/BRE_62.pdf (access date: 29.04.2021).

2. Official site of the Don State Technical University [Electron. resource]. Access mode: https://donstu.ru/ (access date: 02.04.2021).

3. Y.S. Shvets, O. V. Vorontsova, S. G. Sheina, DSTU business center construction project management using energy-saving and information BIM technologies, IOP Conference Series: Materials Science and Engineering, Nalchik, 26-30 September 2020 year, Nalchik, 052009 (2020). DOI 10.1088/1757-899X/913/5/052009.

4. Y.S. Shvets, O. V. Vorontsova, S. G. Sheina, Basic principles of the formation of a student campus development project on the example of Don State Technical University, Materials of the X International Scientific and Practical Conference, March 10-12, 2020.: in 2 parts, Part 1, edited by T.Yu. Ovsyannikova, I.R. Salagor, Tomsk, Publishing house of VSACU 1, 454 (2020).

5. Industry specific code of practice 53-86 (r) Gosgrazhdanstroy, Rules for assessing the physical deterioration of residential buildings [agreed with the Central Statistical Administration of the USSR by the letter of October 29, 1985 N 15-14-414. Approved by the City Duma on April 26, 2011, as amended on March 23, 2020]. Introduced. 198707-01, Ministry of Housing and Communal Services of the RSFSR, Moscow, 1987.

6. Industry specific code of practice 58-88(r) Regulations on the organization and implementation of reconstruction, repair and maintenance of buildings, communal and socio-cultural facilities. Design standards: BCH 58-88(p), Goskomarkhitektura, FSMP, Moscow, 2004.

7. S.A. Baronin, A.G. Yankov, Problems of Science and Education 6, 125-150 (2013).

8. Life cycle costing, Practice guide: bulletin, Canberra (The publications manager Australian national audit office, 2001).

9. Methodology for calculating the life cycle of a residential building, taking into account the cost of total costs, Introduction. 2014-06-04, National Association of Designers, Moscow, 2014.

10. Electronic resource: http://proeco.center/project/raschet-stoimosti-zhiznennogo-tsiklazdaniya (access date 25.02.2021)

11. Vladimir Bazjanac, The implementation of industry foundation classes in simulation tools for the building industry, Lawrence Berkeley National Laboratory Berkeley, CA 94720 Electronic resource: http://www.ibpsa.org/proceedings/BS1997/BS97_P125.pdf (access date 13.03.2021)

12. Digital Design Month: What the Autodesk and ESRI Partnership Means for Government Infrastructure. Electronic resource: https://www.dlt.com/blog/2018/05/01/digitaldesign-month-autodesk-esri-partnership (access date 25.04.2021) 